\section{Las iglesias prefeudales en Álava. Cronotipología y articulación espacial}

\author{
Agustín Azkarate Garai-Olaun, Leandro SÁnchez Zufiaurre \\ Unidad Asociada CSIC/Universidad del País Vasco. Grupo de Arqueología \\ Tardoantigua y Medieval. Arqueología de la Arquitectura (GATMAA)
}

\begin{abstract}
Resumen
El artículo constituye un avance de un proyecto de investigación en curso sobre las iglesias alavesas anteriores a los siglos XII-XIII, invisibles hasta la fecha a una metodología tradicionalmente de base analógica y formal. Se efectúa una nueva propuesta de análisis experimentada ya en la catedral de Santa María de Vitoria-Gasteiz y que se articula de la manera siguiente: 1. Lettura veloce de los principales momentos constructivos de los templos seleccionados con el objeto de individualizar estratigráficamente la fase o fases anteriores al periodo «románico». 2 . Individualización y registro de las variables técnicas y formales más representativas de esta primera fase constructiva en cada una de las iglesias objeto de estudio. 3. Identificación numérica de las variables seleccionadas. 4. Creación de una tabla analítica que recoja la presencia o ausencia de estas variables en cada uno de los edificios a estudiar.

5. Agrupamiento de los edificios que comparten variables entre sí. 6. Transformación de las asociaciones tecnotipológicas en tablas cronotipológicas, es decir, en indicadores cronológicos. Resultado de todo ello ha sido la individualización de seis grupos de iglesias que se articulan diacrónicamente entre los siglos IX y XII. A modo de conclusión se avanzan, finalmente, algunas consideraciones interpretativas sobre la naturaleza de estos templos de época prefeudal.
\end{abstract}

Palabras clave: Iglesias prefeudales; Álava; Cronotipología; Siglos IX-XII; Técnicas constructivas

\begin{abstract}
This article constitutes a preview of a research project into pre-12th to 13 th century churches in Álava, which until now had been invisible to traditional, analogical formal methodologies. It presents a new proposal of an analysis tested already in the cathedral of Santa María de Vitoria-Gasteiz and based along the following lines: 1. Lettura veloce of the main construction stages of temples chosen with the object of stratigraphically determining the phase or phases prior to the Romanesque period. 2. Identification and register of the most representative technical and formal variables of this first phase of construction in each of the churches in the study. 3. Numerical specification of selected variables. 4. Creation of an analytical table to register the presence or absence of these variables in each church. 5. Grouping together those buildings with variables in common. 6.Transformation of technotypological associations in chronotypological tables, i.e., chronological indicators. This has led to the identification of six groups of churches based diachronically between the 9th and 12th centuries. By way of conclusion, some interpretative considerations are put forward as to the nature of these pre-feudal period temples.
\end{abstract}

Key Words: Pre-feudal churches; Álava; Chronotypology; 9th-12th century; Construction techniques.

\section{INTRODUCCION}

Es bien conocido el carácter madrugador de muchas localidades del occidente alavés a la hora de incorporarse al registro escrito altomedieval y son muchos, y buenos, los estudios que se han ocupado de este fenómeno․ Sabemos por ellos que, ya para el siglo IX eran más de diez los núcleos habitados sólo en el valle de Ayala, que otro tanto sucedía en el valle de Valdegovía - a juzgar por los conocidos testimonios del obispo Juan para Valpuesta (año 804) y del abad Abito para Tobillas (822)—, que en el valle de Cuartango eran también diversas las iglesias que se agregaron a San Esteban de Salcedo en el año 873 y que esta ocupación del territorio alcanzó incluso las estribaciones del Gorbea tal y como refleja la donación a San Vicente de Acosta efectuada en el año 871 por el senior Arroncio. Para el siglo X las menciones se multiplican hasta tal punto que renunciaremos a sintetizarlas en este breve texto. La undécima centuria, finalmente, se abre con el famoso documento conocido como «Reja de San Millán» y que recoge más de trescientos núcleos que debían satisfacer bien hierro - en la mayoría de los casos- bien cabezas de ganado al monasterio emilianense.

Sin embargo, son muy pocos los testimonios materiales que tradicionalmente se conocían de aquella espléndida floración de núcleos habitados y que tanto recuerda al famoso pasaje en el que el monje Raoul Glaber alude al blanco manto de iglesias con el que el mundo de su época cubría su vetusta desnudez. Porque, efectivamente, son excepcionales los casos — como el de San Román de Tobillas- en los que los restos materiales conservados son adscribibles al periodo de su primera mención documental. En otros la advocación primitiva del templo mencionado en los siglos altomedievales pervive en el templo actual y cabe pensar que su ubicación siga siendo la misma. Sin embargo las fábricas actuales no conservan el más mínimo resto de los primitivos templos, desaparecidos totalmente ante edificios de culto muy posteriores. Es el caso de San Vicente de Acosta o San Martín de Estavillo, por citar únicamente un par de ejemplos.

Imperceptiblemente, por tanto, se fue extendiendo una cierta desesperanza en la historiografía que acabó por renunciar al conocimiento de aquellas primeras estructuras eclesiales. Así se refleja, por ejemplo, en el testimonio de la más concienzuda y prestigiosa investigadora sobre esta cuestión: "Conocida la existencia de estas iglesias nos preguntamos cómo serían sus edificios. Construidas en momentos

1 Véanse, a modo de ejemplo, los trabajos de J.A. García de Cortázar (1982), R. Martínez Ochoa (1982) o los diversos estudios efectuados por S. Ruiz de Loizaga (1982, 1989, 1995). 
difíciles, los monjes recién llegados o los señores que, con escasos recursos, ocupaban las tierras incultas, las edificarían con pobres materiales: sencilla mampostería, ladrillo, madera y, muy posiblemente, adobe en los edificios anejos, sobre todo en el Suroeste alavés (...). Es muy posible que en los edificios más ricos entre los señalados — Valpuesta, Armentia, Tobillas o San Esteban de Salcedo-, se hubiera empleado piedra labrada y sillería en sus partes más nobles y en sus esquinales; en los muros de la iglesia románica de Tobillas pueden verse - por ejemplo - piedras con motivos incisos, posiblemente del edificio primitivo.» (PORTILLA, 1983: 42)

Las causas de nuestro escaso conocimiento son diversas y no podemos extendernos en su análisis. Sabemos que en un porcentaje importante fueron construcciones lígneas ${ }^{2}$ y, por tanto, hoy en día sólo susceptibles de ser detectadas mediante excavaciones arqueológicas. Únicamente los hábitats rupestres y las iglesias abiertas en la roca — que debieron constituir un porcentaje no desdeñable entre los centros de culto de entonces - nos han permitido acercarnos a la materialidad de los templos altomedievales. Es el caso de los ejemplares rupestres treviñeses, indiscutibles en su morfología y funcionalidad litúrgicas. Su uso como templos cristianos desde el siglo VI hasta, al menos, los siglos XI-XII no parece ofrecer dudas (AZKARATE, 1988) ${ }^{3}$.

Tampoco es ajena, desde luego, a esta enorme laguna en nuestros conocimientos la poca atención que hasta fechas relativamente recientes ha venido mereciendo la arqueología medieval. Pero ésta es una circunstancia que no debe servirnos de excusa permanente para ocultar graves carencias metodológicas y enfoques excesivamente arqueográficos por parte de quienes nos hemos dedicado desde hace algún tiempo a este periodo histórico. Es hora de aventurarnos críticamente a una diagnosis que nos sirva de punto de partida para iniciar una renovación de nuestros instrumentos hermeneúticos. En esta línea, este breve artículo tendrá como objetivo articular una propuesta de análisis metodológico que permite descubrir la existencia de unos

\footnotetext{
2 Aunque no sean muchas las referencias documentales a construcciones de carácter lígneo, son sin embargo suficientemente explícitas: plenariam libertatem ad incidenda ligna montibus meis ad construendas ecclesias, sive aedificandas domos (Cart. Valpuesta, 2, 804); et levabimus matera de quator casas et uno orreo et tectus de tres ecclesias de Valle Posita, et composuimus de ipsa matera casas et eclesial in Villa Merosa, et restaurabimus eas (Cart. Valpuesta, 44, año 975).

3 Son significativos también, a este respecto, los testimonios del monasterio de San Martín, ubicado no lejos de los Castros de Lastra (Caranca) en un emplazamiento protegido y en el que se conservan todavía las huellas de un templo semirrupestre con su necrópolis de tumbas excavadas también en roca (AlONSO et alii, 1992/93).
}

testimonios que, hasta la fecha de hoy, han permanecido ocultos a nuestros ojos.

Son varios ya los trabajos en los que nos hemos referido a las generalizaciones abusivas que, con base en criterios idealistas y analógicos, se acostumbra a efectuar a la hora de articular la secuencia diacrónica de nuestro patrimonio edificado. La tiranía de los analogismos formales y la ausencia de análisis constructivos precisos han distorsionado nuestro conocimiento, favoreciendo la invisibilidad de fases constructivas primitivas que se «ocultaban» en fábricas de cronología posterior o han convertido en románicos templos levantados en los siglos XVII o XVIII. Como señalaba J.M. Pesez, «il est très difficile de cerner la date de construction d'un édifice par les seuls critères habituels de l'histoire de l'art" (1985: 198).

Se ha aducido con frecuencia, para justificar la desaparición de nuestro patrimonio más antiguo, la profunda modificación que han sufrido muchas de las primitivas iglesias altomedievales, sustituidas en momentos de crecimiento económico o demográfico por templos erigidos de nueva planta. A pesar del paso implacable del tiempo y su acción destructora, sin embargo, "no hay nada tan difícil como borrar todas las huellas" de nuestro pasado. "La homogeneidad absoluta es absolutamente rara en el mundo material». Para reconstruir estos mundos perdidos, sin embargo, es en parte necesaria una metodología especial que no puede ser sino el método estratigráfico (CARANDINI, 1997: 256). Recurriremos a este renombrado autor italiano, algo que hacemos con frecuencia, para ilustrar el contexto al que debemos enfrentarnos a la hora de responder al objetivo que más arriba señalábamos.

Si la materialidad de las primitivas iglesias altomedievales alavesas no ha sido observada por los numerosos investigadores que han trabajado aquel periodo es, entre otras razones, porque su presencia no es evidente. $\mathrm{O}$ no lo era, al menos, a los códigos de lectura que hemos venido utilizando. Nos resultaban imperceptibles, no porque no existieran sino porque resultaban invisibles a nuestra manera de mirar las cosas. No éramos capaces de detectar «lo que se encuentra sumergido en el interior de las construcciones». No fuimos conscientes de que, con frecuencia, nos enfrentábamos a «una construcción expoliada de la que apenas queda su propia sombra» y que la comprensión de un determinado lugar «no puede ser justa ni completa si no se controla la superposición y la destrucción de todas las estructuras que allí han surgido a través del tiempo y de las que el edificio todavía en uso no es más que el último representante» ( $I b i-$ dem: 257).

Todo ello nos sitúa en el ámbito de las habilidades instrumentales, en el de la depuración de las técnicas de 

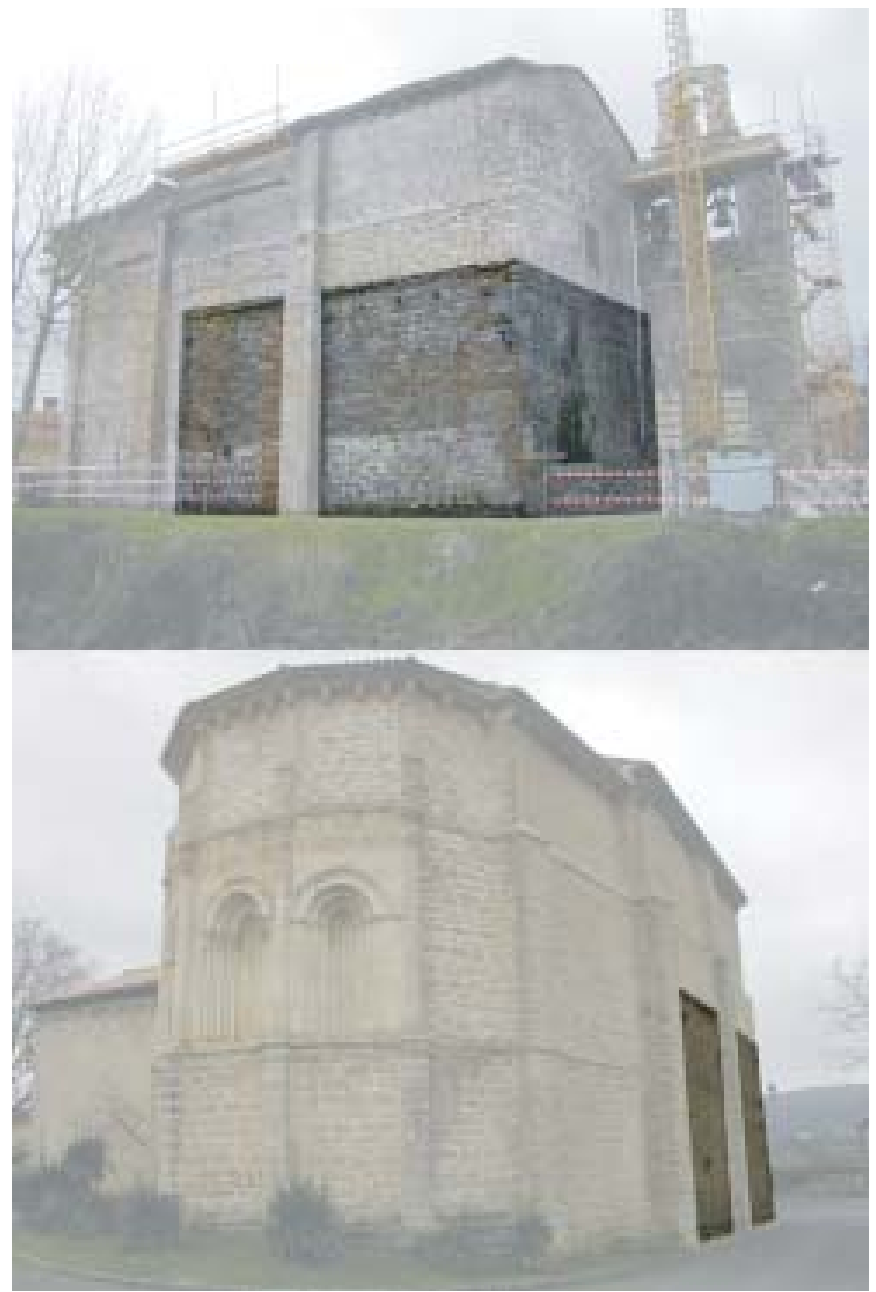

Fig. 1. San Vicente (Hueto Abajo). Puede observarse con claridad cómo el primitivo templo altomedieval quedó abrazado por la ampliación «románica» posterior

análisis. Este breve texto es un modesto ejemplo de una metodología que ya ensayamos en la catedral de Santa María de Vitoria-Gasteiz y que ofreció, creemos, resultados sumamente interesantes. Es también un avance de una tesis doctoral en curso sobre técnicas constructivas del medievo y que viene realizando uno de los arriba firmantes.

Si nos conformáramos con ello, sin embargo, caeríamos en lo que, a modo de denuncia, ha calificado G.P. Brogiolo como hiperestratigrafismo (1997:183). No tenemos que olvidar, en efecto, que la consolidación de una tendencia orientada a investigar, mediante el análisis de los testimonios materiales del pasado, el antiguo contexto social y productivo, se ha revelado, con el tiempo, como una de las aportaciones más importantes de la arqueología medieval y de la arqueología de la arquitectura. Las investigaciones han ido confirmando la idea de que las técnicas constructivas son sólo en parte el producto de la elección formal de los proyectistas y destinatarios, dado que éstos, en sus decisiones, están condicionados inevitablemente por los recursos materiales del territorio y por el contexto histórico y productivo que determina tanto la calidad de los medios de transporte como la disponibilidad de maestros especializados (CAGNANA, 1994: 40). Investigar, por tanto, el uso de técnicas constructivas diversas exige algo más que su secuenciación en un diagrama estratigráfico, algo más -incluso- que su seriación en tablas de carácter cronológico en la medida en que esa diversidad está denunciando, probablemente, la existencia de cambios socioeconómicos que reflejan la mayor o menor capacidad excedentaria de una sociedad y, consecuentemente, su mayor o menor capacidad para controlar ciclos productivos complejos.

Es por ello por lo que aventuraremos también, de manera muy breve, algunas cuestiones sobre el contexto histórico de cada uno de los grupos de iglesias altomedievales que, como se verá, hemos podido detectar en nuestro territorio. Su desarrollo más pormenorizado es uno de los objetivos del trabajo doctoral mencionado, como lo será también la cronotipología que ahora, de manera provisional, avanzamos.

\section{METODOLOGÍA DETRABAJO}

La diócesis de Vitoria cuenta con más de 700 iglesias dispersas por su territorio. Había que racionalizar la búsqueda estableciendo algún criterio con el que pudiéramos establecer una primera criba que redujera el muestreo inicial. Como punto de partida general $-\mathrm{y}$ con intención de obtener un ante quem operativo- se decidió seleccionar todas aquellas iglesias que tuvieran en su edificación actual alguna fase constructiva de lo que en Historia del Arte se ha definido como «románico» y que, en Álava, se inicia a finales del siglo XII. Un vaciado bibliográfico exhaustivo permitió reducir a 326 las iglesias o ermitas a visitar en esta primera etapa del trabajo, número de templos que venía a coincidir aproximadamente con el de las localidades recogidas en la Reja de San Millán de 1025 y en la lista del Arcedianato de Álava de 1257. Teniendo en cuenta que los actuales despoblados alaveses comenzaron a abandonarse a lo largo del siglo XIV y durante la primera mitad del XV (DIAZ DE DURANA, 1986: 121), contábamos con la seguridad razonable de acceder, de esta manera, a la práctica totalidad de las principales iglesias potencialmente altomedievales.

Nuestras experiencias previas en San Román de Tobillas (AzKaraTe, 1995), Andra Mari de Ullíbarri Arana y San Vicente de Hueto Abajo (Solaun, 2003) nos habían permitido constatar la existencia de iglesias «románicas» construidas literalmente "sobre» pequeños templos de época anterior que permanecían, de esta manera, fosilizados en 


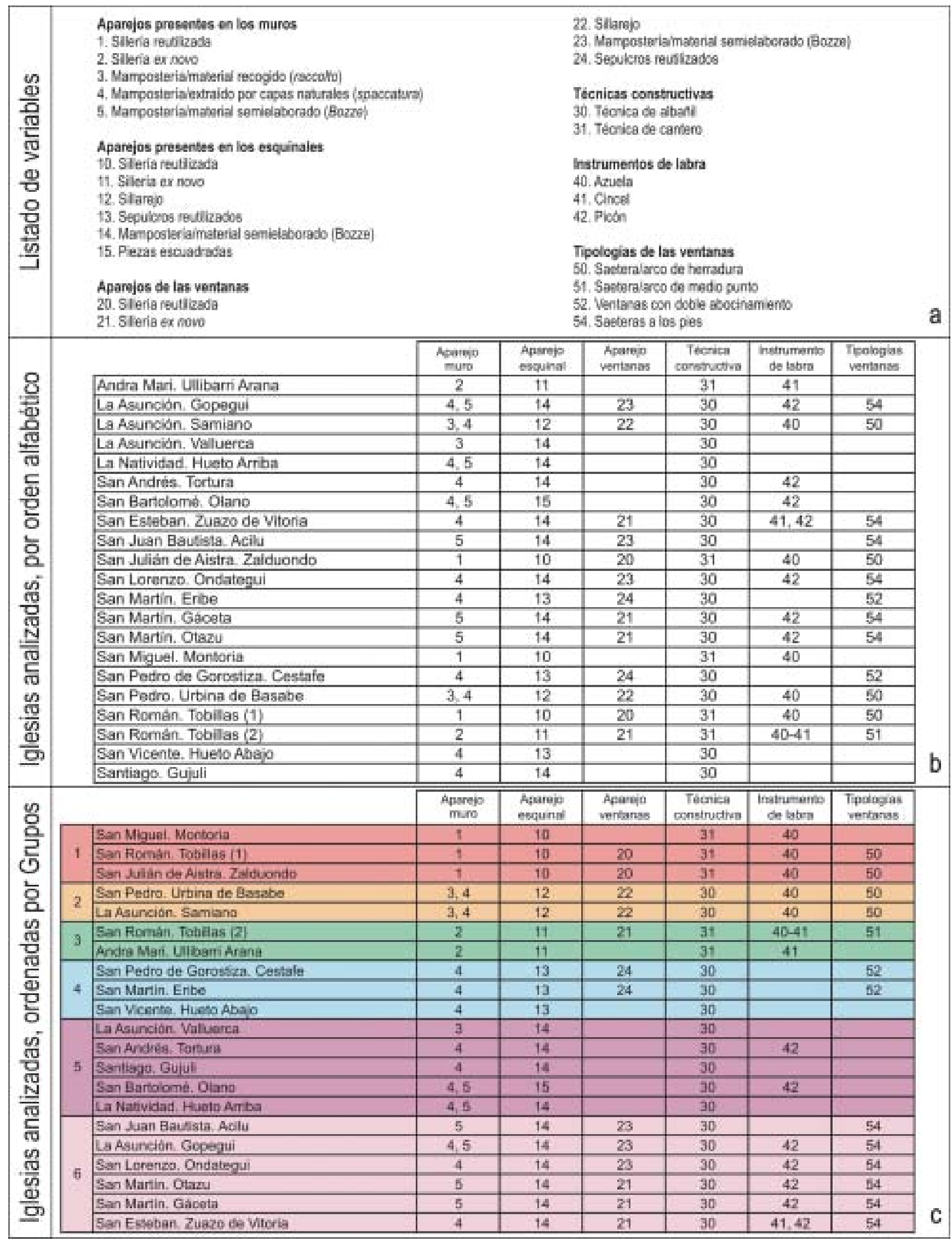

Fig. 2. Mapa de ubicación de las iglesias estudiadas 


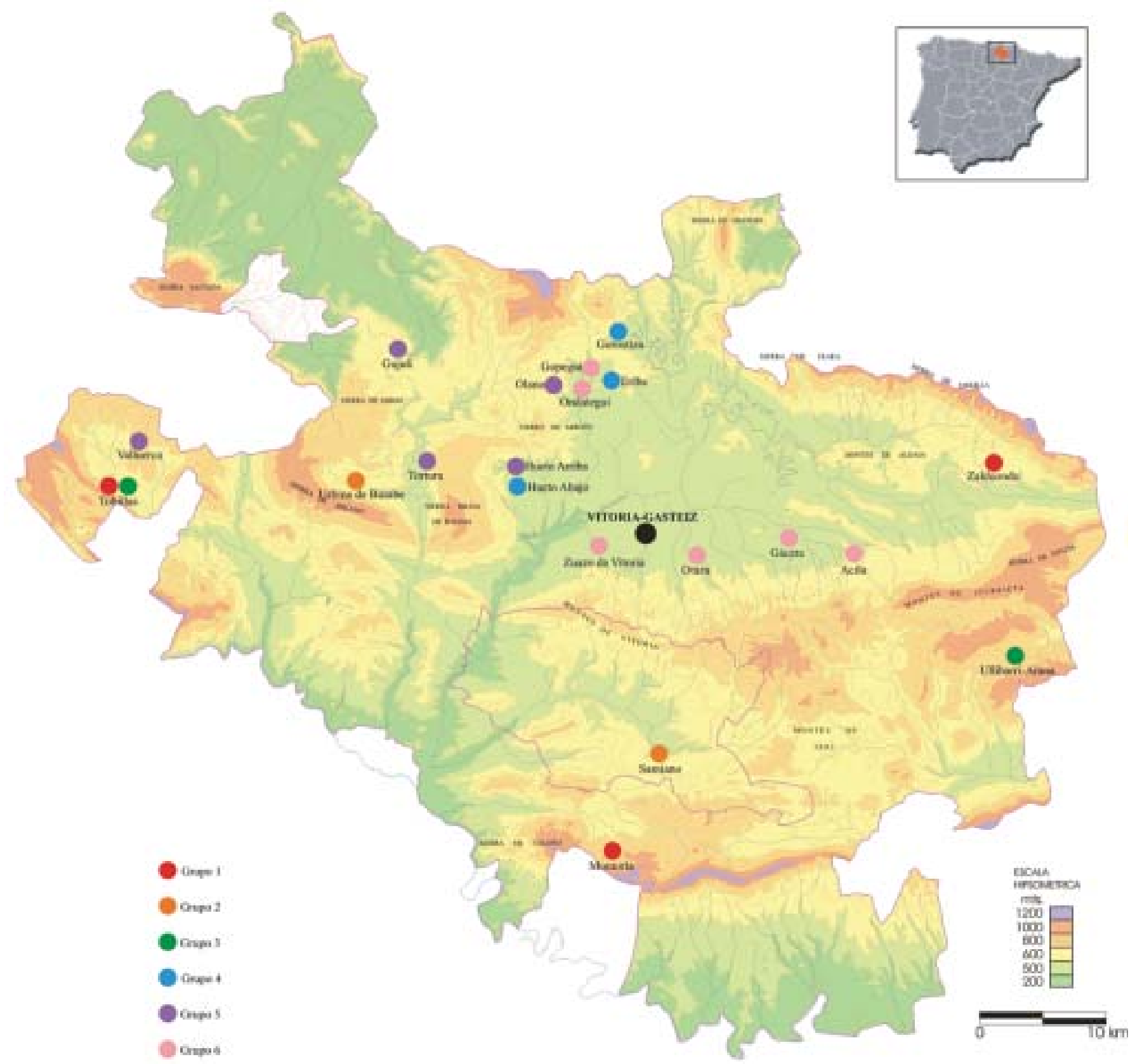

Fig. 3 Mapa de ubicación de las iglesias estudiadas

fábricas más modernas. Cabía suponer que este fenómeno debía observarse también —en mayor o menor medidaen otros edificios. Y así ocurrió, en efecto. Aunque el trabajo de campo no haya sido finalizado en su totalidad, se han podido detectar hasta la fecha una veintena de iglesias en las que cabe detectar el fenómeno descrito.

Fijado el objeto de la investigación, había que articular una metodología que permitiera rentabilizar el trabajo de campo. Una lectura estratigráfica de cada uno de los templos hubiera exigido un esfuerzo más allá de nuestras posibilidades reales, aunque se ha efectuado en los tres casos arriba mencionados y se llevará a cabo en algún otro en un futuro inmediato.

La veintena de edificios detectados ofrecían fábricas de una gran variedad, debido a su construcción con materiales obtenidos en las inmediaciones y aparejados con téc- 
nicas «complejas» ${ }^{4}$ que conllevan, por su propia naturaleza, una notoria heterogeneidad. Se hacía necesario, pues, un esfuerzo de sistematización, articulando la muestra en grupos que compartieran unas mismas características, puesto que es de esperar que, en un mismo ámbito espacio-temporal, las técnicas detectables estuvieran participando de las especificidades propias de los diversos ciclos constructivos. Contábamos, además, con las experiencias cronotipológicas llevadas a cabo en la Catedral de Santa María de VitoriaGasteiz (AZKARATE, 2002) que, en este caso, se han adecuado a las circunstancias específicas de la investigación en curso.

El proceso de trabajo, a ejecutar sistemáticamente en cada uno de los edificios seleccionados, ha sido el siguiente:

1. Lettura veloce de los principales momentos constructivos del edificio con el objeto de individualizar estratigráficamente la fase o fases anteriores al periodo «románico».

2. Individualización y registro de las variables técnicas y formales más representativas de esta primera fase constructiva en cada una de las iglesias objeto de estudio.

3. Identificación numérica de las variables seleccionadas. En nuestro caso fueron seis, cinco de carácter técnico —aparejos muro (1-5), aparejos esquinales (10-15), aparejos ventanas (20-24), técnicas constructivas (30-31), instrumentos de labra (40-42) — y uno formal ${ }^{5}$ — tipología ventanas (50-54)- (Fig. 2).

4. Creación de una tabla analítica que recoja la presencia o ausencia de estas variables en cada uno de los edificios a estudiar (Fig. 2).

5. Agrupamiento de los edificios que comparten variables entre sí (Fig. 2).

6. Transformación de las asociaciones tecnotipológicas en tablas cronotipológicas, es decir, en indicadores cronológicos. Las fuentes documentales en unos casos, las epigráficos en otros o los recursos arqueométricos llegado el caso,

\footnotetext{
4 «Existen técnicas en las que el albañil no se preocupa tanto del aspecto exterior del muro, cuanto de una mayor homogeneidad tridimensional del mismo. Es el caso de la mayor parte de los muros «a seco», y también de muchos muros que van a tener algún tipo de revestimiento. Son las técnicas aparentemente más desordenadas o con un orden menos aparentes, y que es mejor llamar técnicas complejas.» (MANNONI, 1997: 20) (la traducción es nuestra).

5 No incluimos los tipos de planta de las iglesias estudiadas por carecer de suficiente información a este respecto. A diferencia, sin embargo, de lo que se ha observado en Bizkaia donde de tres ejemplares conocidos dos (Momoitio, Ranes) ofrecen planta rectangular sin cabecera marcada (GARCía CAMINO, 2002: 187-193), en los ejemplares alaveses parece dominante la planta de aula rectangular con cabecera diferenciada de testero recto. Tanto en Bizkaia como en Álava las dimensiones conocidas permiten concluir que se trataba de templos que acogían espacios muy reducidos.
}

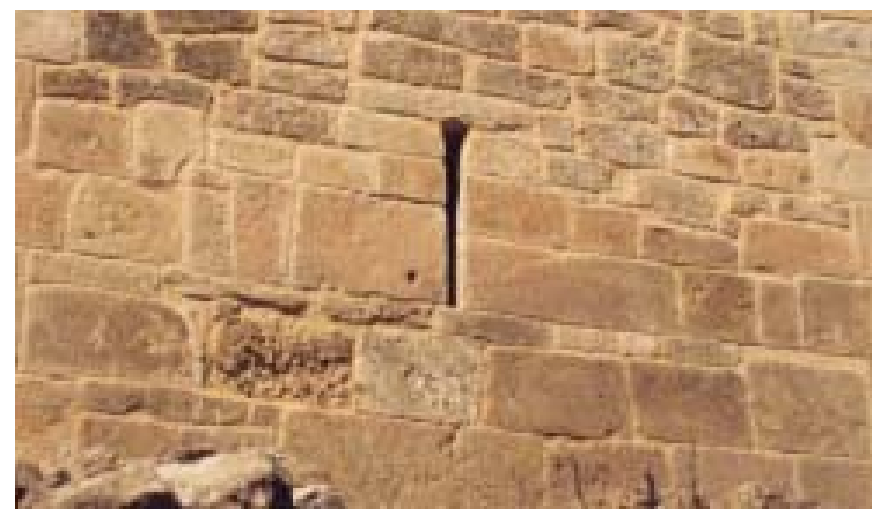

Fig. 4. Imagen de San Román de Tobillas, con dos de las variables más representativas del Grupo 1: ventana rematada en herradura y sillería reutilizada en su aparejo

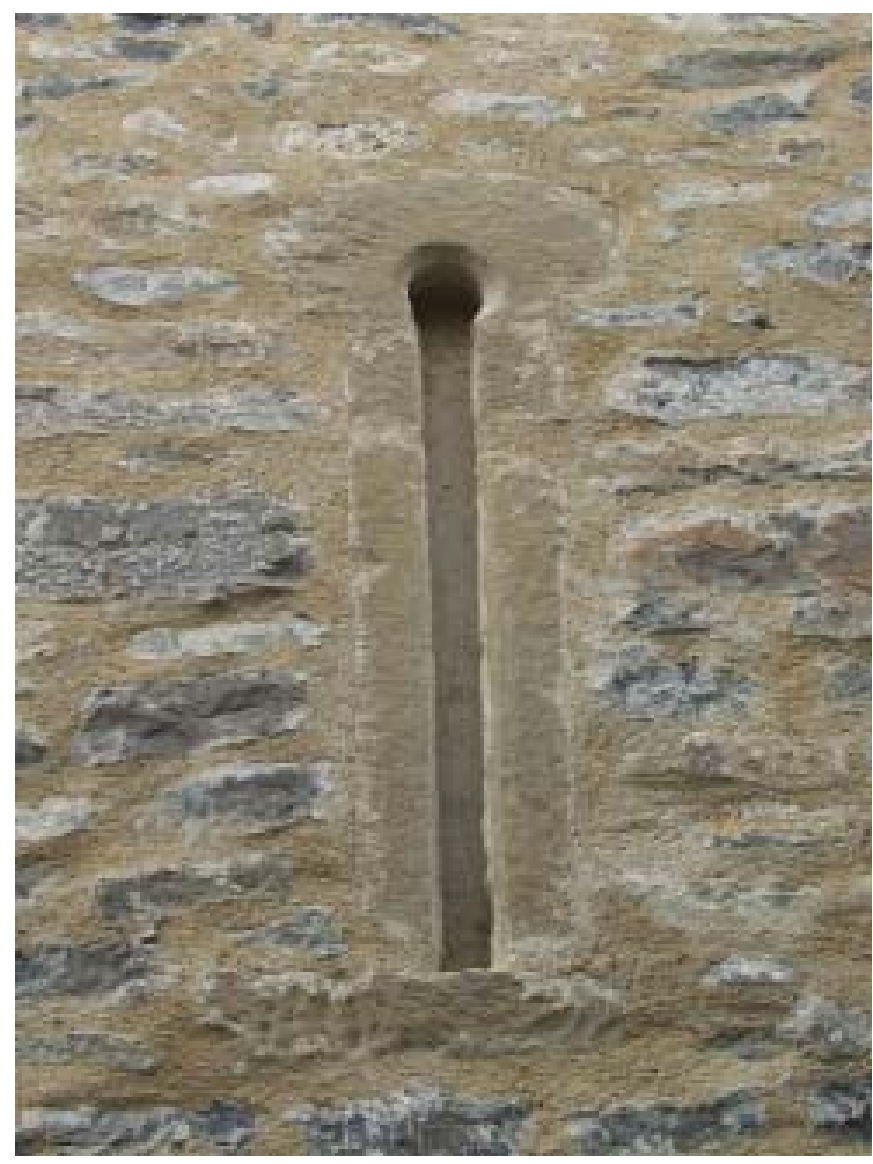

Fig. 5. Imagen de San Pedro (Urbina de Basabe) con algunas variables del Grupo 2: Ventana rematada en arco de herradura, labra en azuela y aparejo de mampostería con material extraído por capas naturales 


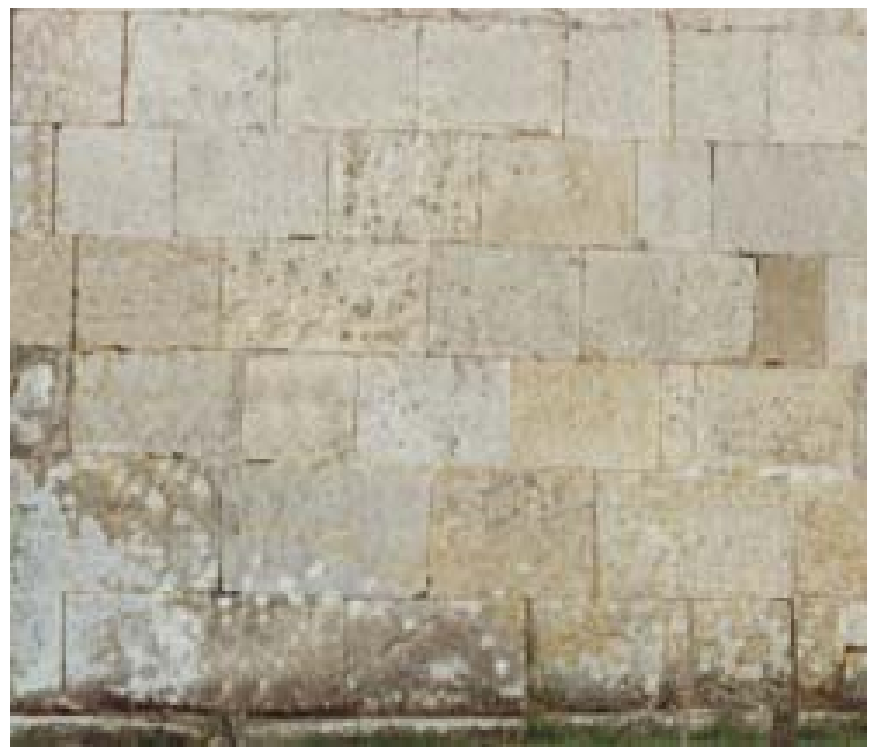

Fig. 6. Aparejo de sillería labrada ex novo de la ermita de Andra Mari de Ullibarri Arana. Grupo 3

están permitiendo y permitirán en el futuro que los resultados del trabajo efectuado constituyan verdaderos indicadores cronológicos de alto valor para la investigación en curso.

\section{AVANCE RESUMIDO DE LOS PRIMEROS RESULTADOS CRONOTIPOLOGICOS}

\section{Grupo 1}

a) Variables: Sillería reutilizada en muros (1), esquinales (10) y ventanas (20). Técnica de cantería (31). Uso de azuela (40). Saetera rematada en herradura (50).

b) Todas las variables que caracterizan a este grupo se encuentran asociadas en la Fase I de San Román de Tobillas (con una fecha documentada: ante quem 822). Similar cronología, pues, cabe suponer para la iglesia de San Julián de Aistra de Zalduondo que reúne también la totalidad de las variables y otro tanto es posible defender también para

\footnotetext{
${ }^{6}$ Aunque queda fuera del trabajo de campo efectuado, es preciso recoger - como perteneciente a este grupo- la iglesia excavada en los Castros de Lastra (Caranca) por F. Saénz de Urturi. De planta rectangular de pequeñas dimensiones (6,70 $3,90 \mathrm{~m}$.), contó con dos vanos rematados en herradura que fueron recuperados en los trabajos de excavación, uno ubicado en el hastial oriental y otro de mayor porte en el hastial opuesto. Contaba con puerta de acceso al sur y para su construcción se recurrió tanto a la caliza como a la toba (SÁENZ De URTURI, 1984, 1985, 1986). De planta también rectangular e igualmente de pequeñas dimensiones fue la iglesia del siglo X descubierta en el subsuelo del Santuario de Nuestra Señora de la Encina (Artzeniega). Posteriormente fue ampliada - tal y como ocurre en los ejemplos aún en pie que recogemos en este trabajo- con otra iglesia románica: los testimonios de ambas fases constructivas han sido exhumados recientemente por las excavaciones arqueológicas llevadas a cabo en el actual Santuario (Torrecilla GorbeA, 1999, 2000).
}

San Miguel de Montoria que carece de una de ellas (50) pero cuya ausencia es perfectamente explicable por haber sido modificado el hastial de su testero en fecha posterior.

Cronología: siglo IX.

c) Iglesias: San Miguel de Montoria, San Román de Tobillas (fase 1), San Julián de Aistra (Zalduondo).

\section{Grupo 2}

a) Variables: Aparejo de mampostería recogida (3) o extraída de cantera por capas naturales (4). Sillarejo en esquinales (12) y en las ventanas (22). Técnica de albañil (30). Azuela en vanos y esquinales (40). Saetera rematada en herradura (50).

b) Carecemos de dataciones absolutas para este segundo grupo. Pero la coincidencia de algunas variables como el uso de la azuela o la presencia de vanos rematados en herradura, sus dimensiones reducidas (característica propia también del grupo anterior) y su emplazamiento asimismo en zonas periféricas y bien protegidas nos llevan a proponer una cronología no lejana a la del Grupo 1, aunque quizá correspondiente ya al siglo siguiente. Urbina de Basabe aparece mencionada ya en el Cartulario de Valpuesta el año 952 y Samiano constituye una de las localidades mencionadas en la Reja (1025).

Cronologia: siglo X.

c) Iglesias: San Pedro de Urbina de Basabe, Nuestra Señora de la Asunción de Samiano 6.

\section{Grupo 3}

a) Variables: Aparejo de sillería ex novo tanto en muros (2) como en esquinales (11) y ventanas (21). Labra a azuela (40) y cincel (41). Saeteras y ventanas abocinadas con remate en arco de medio punto (51).

b) Cuenta con la fechación que le otorga la inscripción que conmemora la restauración efectuada por el presbítero Vigila en el año 939 de nuestra Era (AZKARATE, García Camino, 1996: 127-130). Coinciden, pues, en el tiempo con el grupo anterior.

Cronología: siglo X.

c) Iglesias: San Román de Tobillas (fase 2), Andra Mari de Ullíbarri Arana.

\section{Grupo 4}

a) Variables: Aparejo de mampostería con material tanto recogido (3) como extraído de cantera por capas naturales (4). Reutilización de sepulcros monolíticos tanto para esquinales (13) como para ventanas (24). Técnica de albañil (30).

b) Poseemos datos documentales de interés a la hora de realizar una aproximación cronológica a las iglesias de este grupo. San Pedro es hoy en día una ermita que perte- 


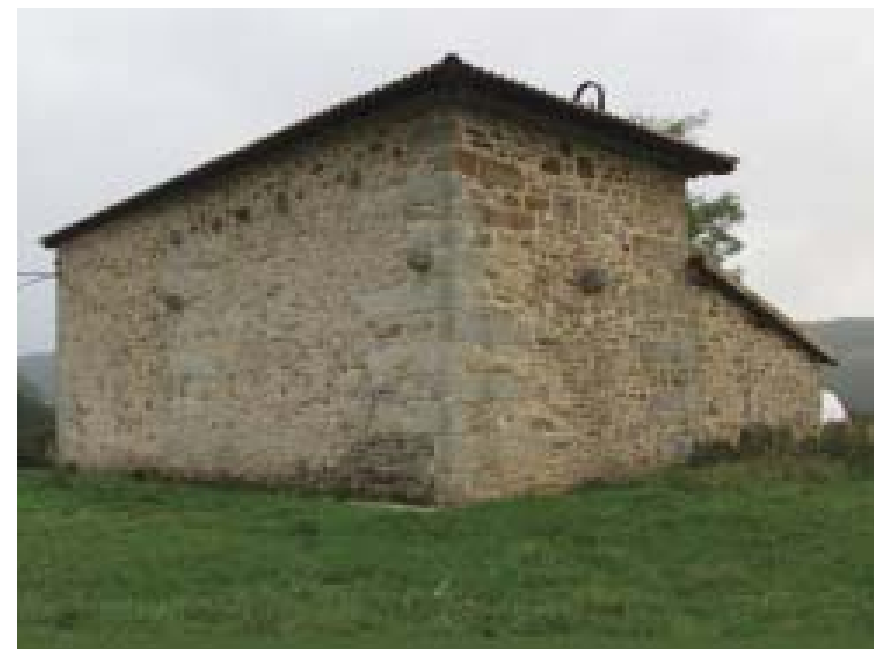

Fig. 7. San Pedro de Gorostiza. En las esquinas pueden apreciarse los sepulcros reutilizados, una de las variables que caracteriza al Grupo 4

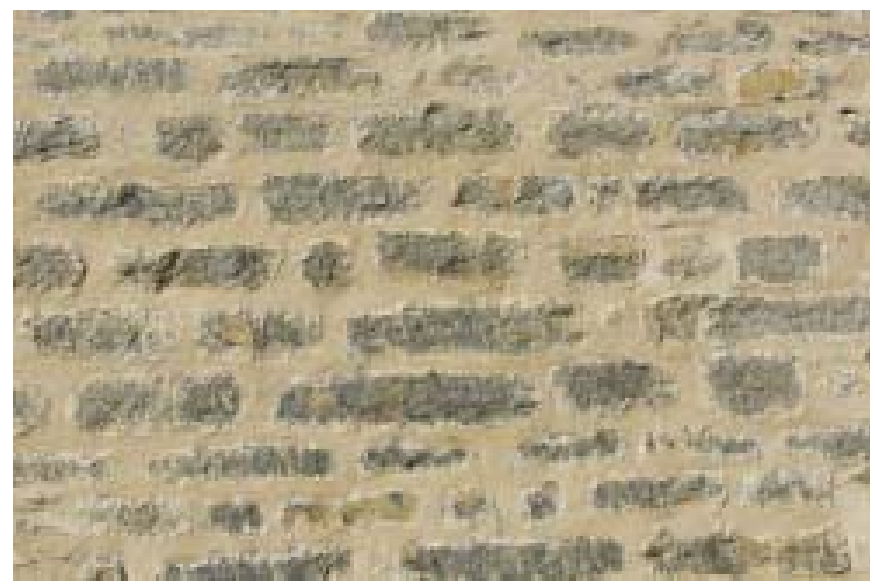

Fig. 8. San Bartolomé de Olano. Grupo 5. Aparejo de mampostería a base de material semielaborado (bozze). El rejuntado reciente hace que las llagas parezcan mayores de lo que lo fueron

neció a Gorostiza, lugar actualmente despoblado que aparece mencionado en la Reja de San Millán en unas donaciones que, en el año 1067, el obispo Nuño y varios nobles efectúan a la iglesia de San Vicente de Acosta: «ego senior Didaco Gondissalvo de Gavari dono (...) in villa Gorostiza, mea portione, cum divisa (Cart. S. Millán, n.o 362). Su fase constructiva "prerrománica» debe pertenecer sin duda a este periodo. La localidad de Hueto aparece recogida también en la Reja de San Millán de 1025. La iglesia fosilizada dentro de la que se erigió posteriormente en «estilo románico» debe corresponder también a la misma época. Podemos, por tanto, presuponer una adscripción cronológica para estos ejemplares en la undécima centuria. De Eribe no tenemos constancia documental hasta la lista del Arcedianato de Alava de 1257. Ello, sin embargo, no resulta cronológicamente determinante porque esta localidad está ubi- cada en la circunscripción de Zuffia de Suso que entrega a San Millán 12 rejas por todo el territorio, sin especificación de núcleos particulares, aún cuando conocemos la existencia de aquellos desde fechas anteriores como en el caso de Acosta (781), Cestafe (871), o Letona (871) que han perdurado hasta la actualidad.

Cronología: siglo XI.

c) Iglesias: San Pedro de Gorostiza, San Martín de Eribe, San Vicente de Hueto Abajo.

\section{Grupo 5}

a) Variables: Muros de mampostería bien recogida (3), bien extraída de cantera por capas naturales (4) bien semielaborada (5). Esquinales con material semielaborado (14) y piezas escuadradas (15).

b) Cronologia: idem grupo 6 .

c) Iglesias: Nuestra Señora de la Asunción de Valluerca, San Andrés de Tortura, Santiago de Gujuli, San Bartolomé de Olano, La Natividad de Hueto Arriba.

\section{Grupo 6}

a) Variables: Muros de mampostería bien extraída de cantera por capas naturales (4) bien semielaborada (5). Material semielaborado también tanto para esquinales (14) como para ventanas (23). Saeteras a los pies articuladas en dos niveles (54).

b) Existen varias iglesias - una (Eribe) mencionada ya en el grupo anterior, tres en este grupo (Tortura, Gujuli Olano), y cuatro en el siguiente (Acilu, Gopegui, Ondategui y Gáceta) - cuya primera documentación es muy tardía (Arcedianato de Alava de 1257). De esta retardada aparición en el registro escrito podría deducirse una cronología igualmente tardía. La conclusión, sin embargo, sería precipitada. Al igual que veíamos en Eribe - y ello resulta altamente significativo- en seis de los siete casos restantes las iglesias aparecen ubicadas en circunscripciones que entregan sus diezmos a San Millán de forma conjunta (Gopegui, Ondategui y Olano en la circunscripción ya mencionada de Zuffía de Suso, Gujuli en la de Urca y Tortura en la de Quartango).

El caso, sin embargo, de Gáceta puede servirnos como indicador cronológico. Esta localidad no aparece mencionada en 1025 a pesar de estar ubicada en la pequeña circunscripción de Hiraszaeza en la que el recaudador de San Millán anota hasta 15 núcleos de poblamiento que deben sus diezmos al monasterio emilianense, alguno de ellos ubicado en sus inmediaciones, como es el caso de Burguellu (actual Elburgo) situado a menos de un kilómetro. Es posible deducir de este hecho significativo que la aparición de Gáceta sea posterior a la fecha de la Reja y convertir este dato en un post quem que permita adscribir las iglesias de los grupos $5 \mathrm{y}$ 
6 a una horquilla cronológica situada entre 1025 y finales del XII o comienzos de la centuria siguiente, fecha en la que el «románico» se extiende por el territorio alavés.

Cronología: siglos XI-XII.

c) Iglesias: San Juan Bautista de Acilu, Nuestra Señora de la Asunción de Gopegui, San Lorenzo de Ondategui, San Martín de Otazu, San Martín de Gáceta, San Esteban de Zuazo de Vitoria.

\section{ALGUNOS APUNTES A MODO DE CONCLUSION}

Hemos de advertir, antes de nada, que el trabajo de campo que se está llevando a cabo en el contexto de la tesis doctoral mencionada no está todavía finalizado. Es probable, por lo tanto, que el mapa que presentamos se modifique en un futuro próximo. Esta circunstancia nos obliga a ser prudentes a la hora de efectuar consideraciones de carácter histórico sobre dinámicas poblacionales o procesos de ocupación del territorio. No es esta nuestra intención ni es éste el marco — por su extrema brevedad - que permita aportaciones de esta naturaleza. Las ideas que se apuntan hay que tomarlas, en consecuencia, como reflexiones que orientarán la investigación en curso.

4.1. Siglos $I X-X$. Llamamos la atención, en primer lugar, sobre la ubicación -no sabemos hasta qué punto significativa- de las iglesias de los siglos IX y X en los márgenes de la Llanada alavesa. Este emplazamiento periférico en valles bien protegidos o a pie de sierra pudiera estar reflejando, quizá, al menos dos cosas: a) En primer lugar, una complicada situación geopolítica, con continuas incursiones musulmanas $^{7}$ que hacían que un territorio como la llanada, abierto y surcado por una iter XXXIV todavía en uso ${ }^{8}$, resultara poco seguro para la prosperidad de asentamientos estables. Es por ello por lo que éstos madrugaron antes en lugares geográficamente más protegidos y adecuados a unas circunstancias como las descritas. b) En segundo lugar, su

\footnotetext{
7 Existe constancia de irrupciones musulmanas en los años 767, 791, $792,794,796,801,803,816,823,825,838,839,842,855,863,865$, 866, 867, 882, 883, 886 (MARTínez DieZ, 1974).

8 Como lo han demostrado las excavaciones arqueológicas llevadas a cabo en Mariturri, asentamiento próximo a Armentia que desde fechas tempranas se ubicó junto a la vieja calzada romana. Las excavaciones han confirmado que ésta continuaba en uso en fechas tardoantiguas y que su trazado seguía vigente en periodo altomedieval como lo demuestra otro iter de dimensiones más reducidas detectado también en los trabajos que se han llevado a cabo. (Información debida a Julio Núñez, director de las excavaciones arqueológicas llevadas a cabo en el asentamiento mencionado).

9268 vacas, 42 yeguas, 85 cerdos, 83 cabras, 16 caballos, siete mulos, 1 asno y un rebaño de ovejas (Cart. S. Millán, 864, n. ${ }^{\circ}$ ).

${ }_{10}$ Constituida por 24 yuntas de bueyes, 100 vacas, 80 yeguas, 20 caballos y mulos, 500 ovejas, pozos de sal en las Salinas de Añana, 24 libros y extensas propiedades distribuidas por Losa, Orduña, Valdegovía, Valluerca, Quintanilla, Acebedo, montes Obarenes, Bureba, Cerezo y Lara.
}

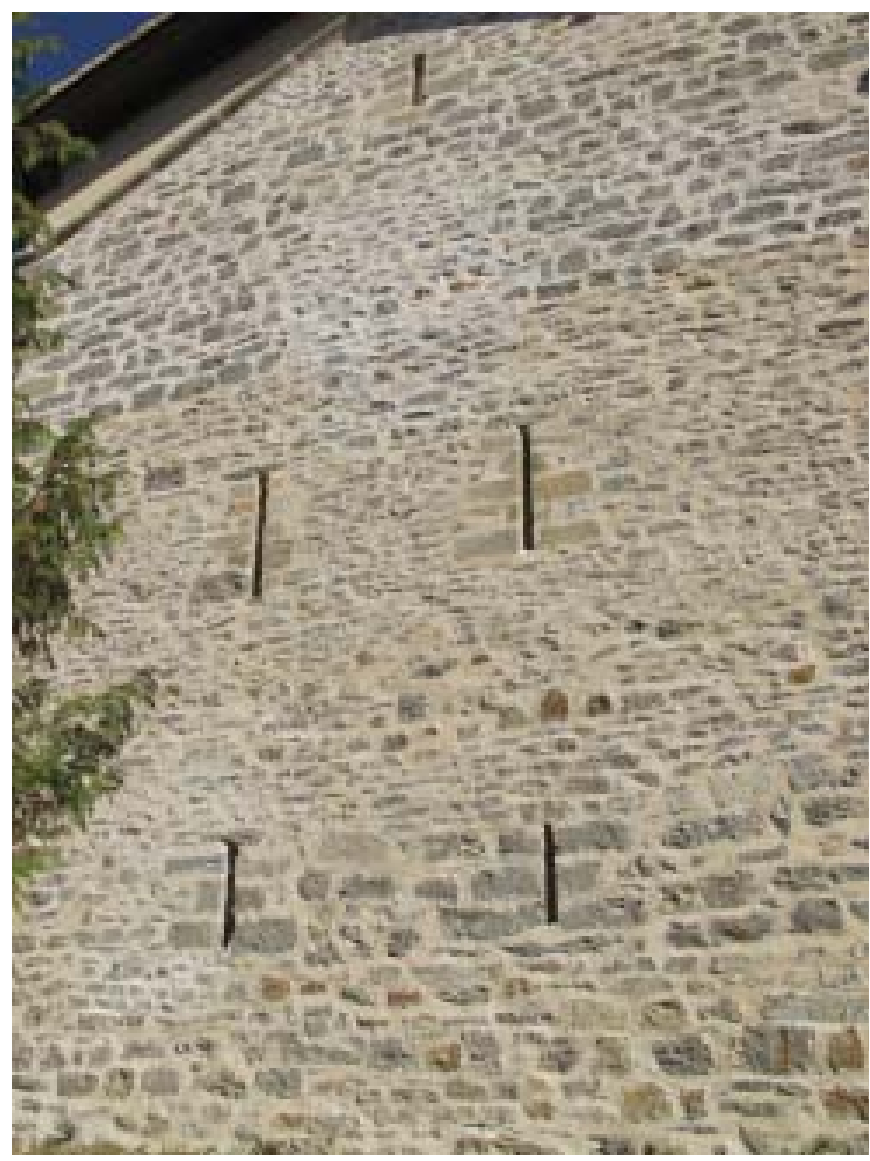

Fig. 9. Nuestra Señora de la Asunción (Gopegui). Vista del hastial occidental, donde se distinguen las cuatro saeteras de la obra original (variable específica del Grupo 6) y el recrecido de la ampliación románica, con una nueva saetera en el remate

emplazamiento pudiera estar reflejando también la dedicación predominantemente ganadera - ya subrayada por la historiografía - de las primeras aristocracias, laicas o eclesiásticas, que se establecen en valles y pies de monte de fácil acceso a los pastos que necesitaban sus animales. Esta dedicación queda atestiguada en el sorprendente número de cabezas de ganado que, en calidad de diezmo, recibía el conde Diego de tres de sus monasterios o iglesias propias ubicados en el valle de Ayala?

$\mathrm{El}$ análisis de las técnicas constructivas permite avanzar algunas otras consideraciones de interés sobre los contextos productivos que permitieron la construcción de aquellos templos primitivos. El Grupo 1 refleja unas capacitaciones (recurso a la técnica de cantería, ejecución de bóvedas sobre pechinas como en el caso de la fase primera de San Román de Tobillas) que sólo pudieron sufragar comitentes perceptores de rentas importantes. La generosa dotación que el abad Avito efectúa al recién fundado monasterio de San Román de Tobillas confirma, en este sentido, las capacidades excedentarias de quien fuera su promotor ${ }^{10}$. 


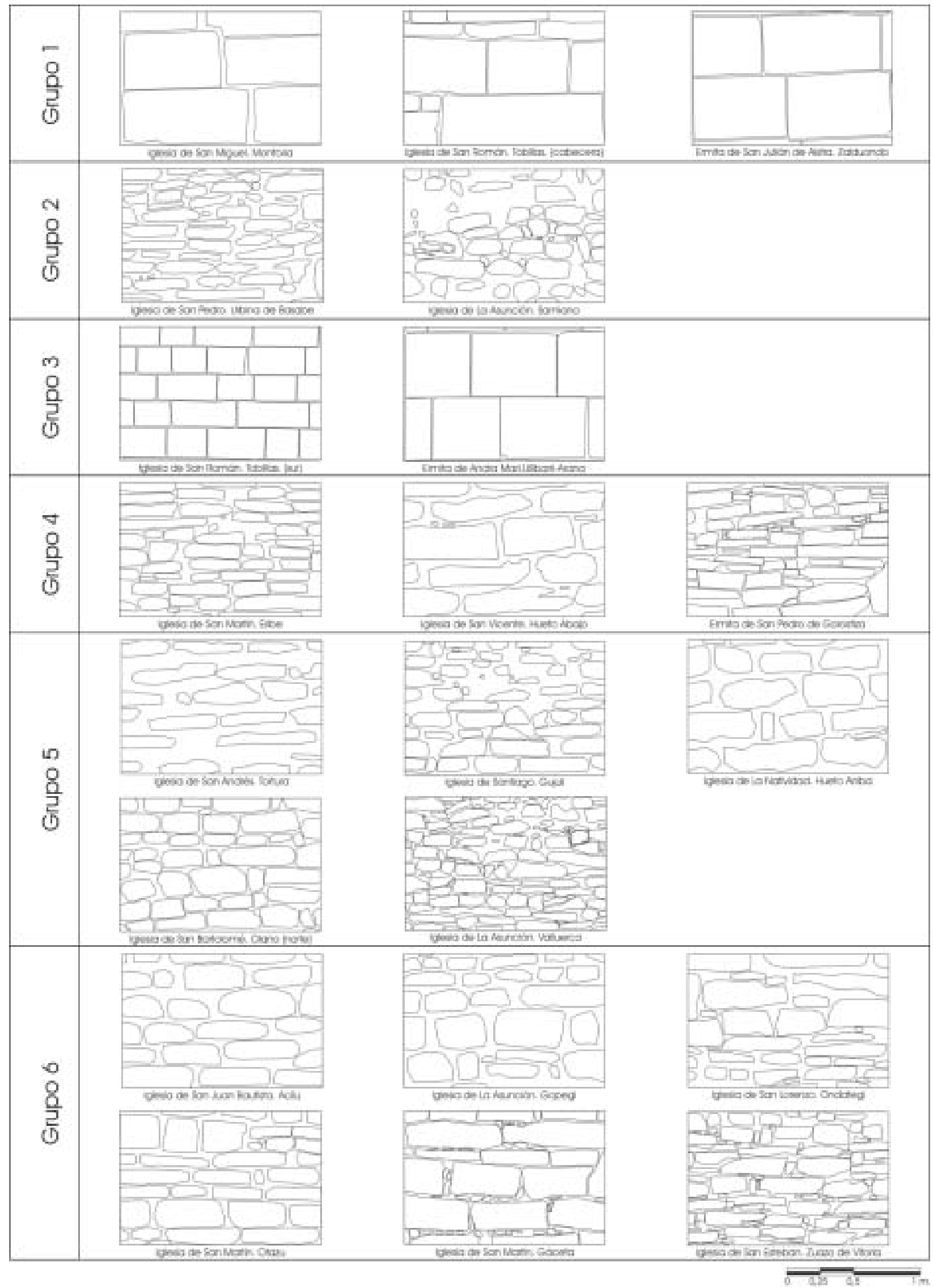

Fig. 10. Relación de los aparejos de las iglesias analizadas, organizados por grupos 
Los dos ejemplares del Grupo 3 constituyen también casos excepcionales. La segunda fase de San Román de Tobillas, llevada a cabo en el año 939 y ejecutada con sillares labrados ex novo para la ocasión, se ha convertido - hasta la fecha- en uno de los testimonios más madrugadores que conocemos para el norte peninsular sobre la recuperación de ciclos constructivos complejos. Tampoco es casual que, en este caso, sea de nuevo un personaje relevante - el presbítero Vigila, emparentado probablemente con la familia condal alavesa- quien lleve adelante una iniciativa de esta naturaleza.

Las iglesias del Grupo 2, en cambio, parecen más propias de comitentes con menos recursos económicos que pudieran ser esos seniores locales que, desde fechas tempranas, comienzan a menudear en la documentación de los principales cartularios: senior Arroncio, dompno Vitulus, dompna Obtavia (871), o también las propias comunidades campesinas que participan, por estas fechas, en un crecimiento agrícola cada vez mejor atestiguado en ámbitos geográficos limítrofes al nuestro (PASTOR, 1996; GARCía CAMINO, 2002). Con menos posibilidades económicas ${ }^{11}$, como decíamos, e incapaces todavía de iniciativas constructivas de mayor porte, recurrieron sin duda a artesanos locales que levantaron sus edificaciones con materiales e instrumentos que denuncian el predominio del albañil sobre otros artesanos de mayores conocimientos técnicos.

4.2. Siglos XI-XII. Los templos de los grupos 4-6, de cronología más tardía adscribible a los siglos XI y XII, van ocupando ya espacios más centrados que, significativamente, comienzan a jalonar ya la vieja iter XXXIV. Su presencia y diversificación responde al crecimiento económico que acompañó al cambio de milenio.

11 Para la cuestión de los escasos recursos de las aristocracias de los primeros siglos altomedievales, cfr. WICKHAM, 1989: 30.

${ }^{12}$ No hay que olvidar, sin embargo, la posibilidad de que la fijación de las comunidades campesinas precediera en algunos casos a la aparición de las iglesias. En el caso de Gasteiz, por ejemplo, hemos documentado un asentamiento estable desde el siglo VIII en adelante, pero la primera iglesia detectada hasta el momento en las excavaciones arqueológicas no puede llevarse más allá de finales del siglo XI. I. García Camino ha prestado atención a esta cuestión en su magnífico trabajo sobre Bizkaia (GARCía CAMINO, 2002).

${ }^{13}$ En relación con todo ello, parece que estaremos obligados a plantear en un futuro próximo algunas cuestiones que no han recibido excesiva atención en la historiografía de nuestro entorno. Por ejemplo, la cuestión bien conocida en otras latitudes de los sacrarios o «sagrers» catalanas, e ignorada sin embargo en nuestro ámbito geográfico a pesar de que existen indicios suficientes de su existencia. En la necrópolis vizcaína de Momoitio, por ejemplo, fueron detectados diversos agujeros tallados en roca que delimitaban, por el oeste, el ámbito del cementerio (GARCIA CAMINO, 2002: 113-114). Las excavaciones arqueológicas que estamos llevando a cabo en la antigua sede episcopal de San Andrés de Armentia están ofreciendo datos de la máxima relevancia reacionados con este punto.
Muchas de estas iglesias - tanto en estos casos como en los de las dos centurias anteriores-, fueron con toda seguridad agentes activos que coadyuvaron a la fijación del poblamiento campesino en el proceso de crecimiento que se detecta a partir del siglo VIII ${ }^{12}$. Que en algunos casos fueron, además, centros perceptores de las rentas señoriales es cosa admitida ya por la historiografía y queda comprobada también en nuestro caso por los silos que, cada vez con más frecuencia, se están detectando en las excavaciones arqueológicas o las estructuras anexas que algunas iglesias tuvieron - tal y como denuncian las ménsulas conservadas generalmente en sus fachadas septentrionales - y que debieron funcionar a modo de cellarii. Finalmente no hay que olvidar tampoco el carácter representativo que alcanzaron, sobre todo las de los siglos XI-XII como símbolos del paulatino aumento del poder señorial. Resultan del máximo interés, en este sentido, las iglesias del grupo 6, caracterizadas por su hastial occidental articulado en dos niveles de saeteras que traslucen la existencia de otros tantos forjados interiores y que invitan a interpretaciones sobre su funcionalidad del máximo interés ${ }^{13}$.

$$
* * *
$$

Cuando la gran movilización de recursos propios de una sociedad ya feudal permita la construcción de las iglesias que llamamos «románicas» a partir de la segunda mitad del siglo XII y sobre todo a lo largo de la centuria siguiente, el futuro deparará distinta suerte a los pequeños templos que habían ido floreciendo durante los siglos altomedievales.

-Bastantes de ellos continuaron como parroquias y como tales han perdurado hasta nuestros días. Sus primitivas fábricas han desaparecido completamente en muchos casos, pero en otros, afortunadamente, han quedado fosilizadas en las estructuras románicas que las substituyeron. Es el ejemplo, bastante paradigmático, de Hueto Abajo. Tal y como se refleja en la imagen que presentamos (Fig. 1), la pequeña iglesia altomedieval pervive aún como humilde testimonio semioculto en la potente estructura de fábrica del siglo XIII; una construcción ésta que luce orgullosa el poder económico de unos comitentes capaces de sufragar el coste generado por unos ciclos productivos mucho más especializados.

-Otros templos pervivieron como iglesias parroquiales durante algún tiempo y fueron ampliados incluso en los siglos XII y XIII, pero los núcleos a los que servían acabaron despoblándose y quedan hoy como simples ermitas rurales. Es el caso de San Pedro de Gorostiza que en el siglo XIII es parroquia todavía del Arciprestazgo de Cigoitia (CARO BAROJA, 1983: 143), pero que se transformó en "mortuorio» ya para el siglo XVII (LÓPEZ DE GUEREÑU, 1989: 551). 
- Hubo, finalmente, pequeños templos altomedievales que no prosperaron de ninguna de las maneras descritas y quedaron como humildes ermitas o, simplemente, como hagiotopónimos fosilizados. Así ocurrió, entre otras muchas, con las iglesias de San Victor de Gardea en Llodio (Cart. San Millán, n. ${ }^{\circ}$ 15, año 873; n. ${ }^{\circ}$ 85, año 964), San Martín de Monte (Cart. San Millán, n. $\left.{ }^{\circ} 15,873\right)$, San Milán y Santiago de Abecia (Car. San Millán, n.o 24, año 937), etc.

En cualquier caso, el conocimiento más exhaustivo de este proceso aportaría mucha luz a un periodo poco conocido todavía entre nosotros. En este sentido, sería deseable que investigaciones como ésta que esbozamos de forma excesivamente breve, se fueran realizando de manera sistemática en otros territorios porque es casi seguro que son muchos todavía los testimonios altomedievales que siguen resultando invisibles aunque "estén ahí», a la espera de ser descubiertos.

\section{Bibliografía}

Alonso J. F., CASTellet S., Fernández E., 1992/93, La necrópolis de San Martín de Valparaiso (Villanueva de Valdegobia, Álava), Kobie (Serie Paleoantropoogia) XX, pp. 157-186.

Azkarate Garai-Olaun A., 1988, Arqueología cristiana de la antigüedad tardía en Alava, Guipúzcoa y Vizcaya, Vitoria.

Azkarate Garai-Olaun A., 1995, Aportaciones al debate sobre la arquitectura prerrománica peninsular: la iglesia de San Román de Tobillas (Álava), Archivo Español de Arqueologia 68, pp. 189-214.

AZKARATE GARAI-Olaun A., 2002, Intereses cognoscitivos y praxis social en Arqueología de la Arquitectura, Arqueología de la Arquitectura 1, pp. 55-71.

AZKarate A., FernándeZ de Jáuregui A., NúŃEZ, J., 1995, Documentación y análisis arquitectónico en el País Vasco. Algunas experiencias llevadas a cabo en Álava-España, Leer el Documento Construido, Informes de la Construcción, vol 46, n. ${ }^{\circ} 435$, pp. 65-78.

Azkarate Garai-Olaun A., García Camino I., 1996, Estelas e inscripciones medievales del País Vasco (siglos VI-XI), I. País Vasco Occidental, Vitoria.

BRogiolo G. P., 1997, Dall'analisi stratigrafica degli elevati all'archeologia dell'architettura, Archeologia della Architettura 2, pp. 181-184.

CaGnANA A., 1994, Archeologia della produzione fra tardo-antico e altomedioevo: le tecniche murarie e l'organizzazione dei cantieri, Edilizia Residenziale tra V e VIII secolo, Mantova.

Cagnana A., 2000, Archeologia dei materiali da costruzione, Mantova.

Carandini A., 1997, Historias en la tierra. Manual de excavación arqueológica, Barcelona.
Caro Baroja J., 1983, Álava en la llamada "Reja de San Millán», Historia General del País Vasco, Tomo 3, Edad Media I, pp. 109-149.

Díaz De Durana J. R., 1986, Álava en la Baja Edad Media: crisis, recuperación y transformaciones socioeconómicas (c.1250-1525), Vitoria.

GARCía CAMINO I., 2002, Arqueología y poblamiento en Bizkaia, siglos VI-XII: la configuración de la sociedad feudal, Bilbao.

GARCíA DE CORTÁZAR J. A, 1982, La sociedad alavesa medieval antes de la concesión del fuero de Vitoria, Vitoria en la Edad Media, Vitoria, pp. 89-114.

Ledesma Rubio, M. L., 1989, Cartulario de San Millán de la Cogolla (1076-1200), Zaragoza.

Mannoni T., 1984, Metodi di datazione dell'edilizia storica, Archeologia Medievale XI, pp. 396-401.

Mannoni T., Giannichedda E., 1996, Archeologia della produzione, Torino.

MANNONI T., 1997, Il problema complesso delle murature storiche in pietra 1. Cultura materiale e cronotipologia, Archeologia dell'architettura II, pp. 15-24.

MarTínez Díez, G., 1974, Álava Medieval I, Vitoria.

Martínez OchOA, R. M., 1982, Aspectos de la ocupación del espacio en los valles de Ayala y del Bayas en los siglos IX al XI, Vitoria en la Edad Media, Vitoria, pp. 695-710.

PARENTI R., 1988, Le tecniche di documentazione per una lettura stratigrafica dell'elevato, Archeologia e restauro dei monumenti, Florencia, pp. 249-279.

Pérez Soler M. D., 1970, Cartulario de Valpuesta, Valencia.

Pesez, J. M., 1985, La renaissance de la construction en pierre après l'An Mil, Pierre \& Métal dans le bâtiment au Moyen Age, París, pp. 197-207.

Pastor Díaz De Garayo E., 1996, Castilla en el tránsito de la antigüedad al feudalismo. Poblamiento, poder político y estructura social del Arlanza al Duero (siglos VII-XI), Valladolid.

Portilla Vitoria M. et alii, 1967-2001, Catálogo monumental de la Diócesis de Vitoria, 8 Tomos, Vitoria.

Portilla Vitoria M., 1983, Arte románico. Raíces y evolución, Álava en sus manos, Tomo IV, Vitoria, pp. 41-72.

Ruiz DE Loizaga S., 1982, Monasterios altomedievales del occidente de Álava: Valdegovía: cómo nacen los pueblos, Vitoria.

RUIZ DE LoIZAGa S., 1989, Repoblación y religiosidad popular en el occidente de Álava: (siglos IX-XII), Vitoria.

RUIZ DE LOIZAGA S., 1991, Iglesia y sociedad en el norte de España: (Iglesia Episcopal de Valpuesta, Alta Edad Media), Burgos.

RuIZ DE LoIZAGA S., 1995, Lengua y cultura en Álava (ss. IX-XIII), Burgos.

SÁENZ De URTURI F., 1984-86, Los Castros de Lastra, Arkeoikuska 83-85, Vitoria

Solaun Bustinza J. L., 2003, Iglesia de San Vicente de Hueto Abajo, Arkeoikuska 02, pp. 316-323.

Torecilla Gorbea M., 1999-2000, Santuario de Nuestra Señora de la Encina (Artziniega), Arkeoikuska 98-99, Vitoria.

Ubieto Arteta A., 1976, Cartulario de San Millán de la Cogolla: (759-1076), Valencia.

WiскнAм C., 1989, La otra transición: del mundo antiguo al feudalismo, Studia Historica. Historia Medieval, VII, pp. 7-35. 